Published in final edited form as:

Am J Disaster Med. 2016 ; 11(1): 49-58. doi:10.5055/ajdm.2016.0224.

\title{
Injury-related fatalities in selected governorates of Iraq from 2010 to 2013: Prospective surveillance
}

\author{
Oleg O. Bilukha, MD, PhD, \\ Emergency Response and Recovery Branch, Division of Global Health Protection, Center for \\ Global Health, Centers for Disease Control and Prevention, Atlanta, Georgia
}

\author{
Abdul-Salam Saleh Sultan, MBChB, DM, \\ Human Resources Training and Development Center, Ministry of Health, Baghdad, Iraq
}

\author{
Ahmed Hassan, MBChB, FICMS, \\ Medical Operations and Specialized Services Directorate, Operations Department, Ministry of \\ Health, Baghdad, Iraq \\ Syed Jaffar Hussain, MD, and \\ World Health Organization, International Zone, UNAMI Compound, Baghdad, Iraq

\section{Eva Leidman, MSPH} \\ Emergency Response and Recovery Branch, Division of Global Health Protection, Center for \\ Global Health, Centers for Disease Control and Prevention, Atlanta, Georgia
}

\section{Abstract \\ Objective-After several years of relative stability in Iraq, the emergence of the Islamic State militant group has spurred a resurgence of violence. This study explores the impact of the conflict on the overall injury profile to estimate the proportion of injury fatalities related to conflict and better understand how violence has affected nonconflict-related injuries.}

Design-Routine prospective injury surveillance operated by the Iraqi Ministry of Health.

Setting-Surveillance data were collected from coroner offices in eight pilot governorates: AlAnbar, Baghdad, Basrah, Erbil, Kerbala, Maysan, Ninevah, and Al-Sulaimaniya.

Participants-We analyzed all fatalities from external injury causes recorded between January 1, 2010 and December 31, 2013. Analysis included 32,664 fatal injuries.

Results-Of all injury fatalities reported, 27.1 percent were conflict-related fatalities, approximately the same proportion as road traffic-related fatalities (24.4 percent) and other unintentional injuries (27.5 percent). The proportion of fatalities from conflict was approximately three times higher among males than females ( 33.0 percent and 10.3 percent, respectively) and four times higher among adults than children ( 29.8 percent and 7.3 percent, respectively). The total number of injury fatalities remained stable between 2010 and 2012; an increase in injury fatalities in 2013 was driven primarily by increases in fatalities from both interpersonal violence and conflict.

Conclusions-From 2010 to 2013, nearly one in four injury fatalities in Iraq was attributable to conflict, a notably higher proportion than other conflict-affected countries in the region. The 
overall profile of nonconflict injuries in Iraq is also distinct from other countries of similar socioeconomic level that have not experienced violence.

\section{Keywords}

death certificates; information systems; international; mortality; surveillance

\section{Introduction}

Iraq provides a unique data source to examine the structure of injuries in a more developed country affected by conflict. Most countries globally experiencing high levels of conflict, such as Afghanistan, Democratic Republic of Congo, Nigeria, Pakistan, South Sudan, Syria, Yemen, are low- or lower-middle-income countries. ${ }^{1}$ World Health Organization (WHO) estimates suggest that globally almost all fatalities due to conflict or war were reported in low- and lower-middle-income countries. ${ }^{2,3}$ Iraq, by contrast, is an upper-middle-income country according to the World Banks' gross national income per capital classifications. ${ }^{1}$

Few conflict-affected countries globally have reliable data on injury fatalities; in the subset classified as middle income, the number of countries is even fewer. A global review of data in the WHO mortality database found that as of 2010, only 83 countries globally had current all-cause mortality data, and of those only 20 were classified as high quality. ${ }^{4}$ Recent mortality surveillance data were available in most high-income countries; however, coverage in conflict-affected countries, low- and middle-income countries, and countries in the Africa regions was much lower. In the North Africa and the Middle East region, for example, countries comprising more than 80 percent of the population in this region had no available data on cause of death. ${ }^{4}$ At the time of the aforementioned review, Iraq lacked reliable injury data but has since worked to improve data availability with the establishment of facilitybased surveillance referred to as the Injury Mortality Surveillance System.

There has been extensive research on mortality from the conflict in Iraq; however, most efforts have focused on estimating the number of deaths attributable to the conflict rather than the overall structure of injury mortality. ${ }^{5-9}$ Such analysis enables us to answer several key questions. First, we can assess the share of conflict-related fatalities among all fatal injuries to help characterize the relative burden of conflict on the health system. Second, we can examine the overall structure of nonconflict-related injuries, to determine if they follow a pattern similar to middle-income countries not affected by conflict.

The recent history of Iraq allows us to explore both questions during a period of stabilization characterized by relatively low levels of conflict as well as during the resurgence of violence. The US-led military coalition occupied Iraq for nearly 8 years, from 2003 to 2011. Conflict and mortality attributed to the violence previously peaked in 2006.,10 Throughout this period, insurgency groups sustained violent attacks. Between 2010 and 2012, during the scale down and withdrawal of US troops, Iraq experienced a period of stability. Conflict was sustained at relatively low levels and concentrated in a few select governorates. ${ }^{10,11}$ However, in early 2013, the situation began to deteriorate with rates of violence escalating to levels comparable to $2006 .{ }^{10}$ 
To better understand how the injury profile in conflict-affected countries is distinct from countries without conflict, we studied the overall structure-the relative proportion of injuries attributed to different mechanisms - of all reported injury fatalities. Our analysis compared the structure of fatal injuries overall and disaggregated by demographic groups. We present time-trends to examine how the injury profile changed as Iraq transitioned from a period of stabilization to a resurgence of violence.

\section{Methods}

Data on all injury fatalities reported between January 1, 2010, and December 31, 2013, were obtained from the Injury Mortality Surveillance System. The surveillance system is operated by the Iraqi Ministry of Health $(\mathrm{MoH})$ and the Kurdistan Regional Government Ministry of Health with technical support from the World Health Organization and the Centers for Disease Control and Prevention.

Analysis presented here includes data on all deaths from injury reported by coroner offices in all pilot governorates. Pilot governorates included Al-Anbar, Baghdad, Al-Basra, Erbil, Kerbala, Maysan, Ninevah, and Al-Sulaimaniya. MoH selected governorates based on capacity of coroner staff and willingness to participate, taking into consideration geographic distribution, population density, and level of conflict of the governorates. These governorates represent northern, central, and southern parts of Iraq and include approximately 60 percent of the total Iraqi population. ${ }^{12}$ On average, 72.8 percent of the population per governorate lives in urban centers in the eight governorates included in surveillance (range: 48.4-87.2 percent), similar to the national average (65.9 percent; range 43.7-87.2 percent). ${ }^{13}$ Both governorates affected by insecurity and insurgency activity (Al-Anbar, Baghdad, and Ninevah) as well as governorates that have been relatively stable (Al-Basra, Erbil, Kerbala, Maysan, and Al-Sulaimaniya) were included.

The case definition used by surveillance included all persons who died as a result of an external injury. While fatalities that occurred in police custody (eg, while incarcerated) were included in the system, fatalities resulting from legal intervention (action by police) were not included. Due to cultural sensitivities, deaths resulting from interpersonal violence in the context of sexual assault were classified as "interpersonal violence" with the requisite mechanism of injury (eg, firearm, blunt, or sharp object) without sexual assault mentioned as a cause. All road-traffic injuries were considered unintentional injuries. Injuries determined to be the result of insurgency activities were all classified as conflict related, which corresponds to the category forces of war and nature used in the global databases. ${ }^{14}$ Multiple fatalities injured in a single incident were each independently recorded. For comparability with global databases, children were defined as persons younger than 15 years.

Our analytic focus considered both intent and mechanism categories. Surveillance forms allowed for classification of injuries into more than 30 mechanism categories. Coroners determined the mechanism, classifying injuries by the primary cause of injury. Injuries were classified into six intention categories, including two unintentional categories (road traffic injuries and other unintentional injuries), three intentional categories (self-harm, interpersonal violence, and conflict related), as well as undetermined intent. Intent and 
mechanism were independently determined by clerks at all coroner offices in selected governorates who were trained to extract this information from physical examinations and reports from police and family members. The date and location of incident, victim demographics, death certificate number and date of issue, and circumstances of the incident were also recorded on the standardized surveillance form. Trained clerks entered completed surveillance forms at least once a week. Encrypted datasets were transmitted monthly to the $\mathrm{MoH}$ for aggregate analysis.

We checked the database for duplicate entries by comparing victim demographics, the time and location of incident, and mechanism of injury. Population estimates used are projections by the Iraq Central Organization for Statistics and Information Technology (COSIT). ${ }^{12}$ Data were collected using a standardized questionnaire developed in EpiInfo. Statistical analysis was performed using STATA statistical software (version 14.0). The Institutional Review Board of the Centers for Disease Control and Prevention determined this study to be "nonresearch" because it entailed secondary analysis of routinely collected public health surveillance data. Personal identifiers were not included in the final dataset used for analysis.

\section{Results}

A total of 32,664 fatalities due to external injuries were reported by coroner offices between January 2010 and December 2013 in the eight Iraqi governorates under surveillance. Overall, 23,849 (73.0 percent) fatalities were among males and 8,673 (26.6 percent) fatalities were among females. Sex was undetermined for 0.4 percent of fatalities. Of all fatalities, 5,448 (16.7 percent) were children younger than 15 years and 25,054 (76.7 percent) of fatalities were adults. The age of 2,162 (6.6 percent) fatalities was undetermined. Among fatalities with known sex, children represented a larger proportion of fatalities among females compared to males, 22.6 and 14.6 percent, respectively. The highest numbers of fatalities were in the age category 20-24 years for females and in the two 5-year age categories from 20 to 29 years for males. Both the number and rates of fatal injuries were greater for males than females across all 5-year age categories (Figure 1).

Among all fatalities, we document approximately equal numbers of road traffic, other unintentional, and conflict-related injury fatalities—road traffic fatalities contributed 7,976 (24.4 percent of all fatalities), other unintentional fatalities contributed 8,985 (27.5 percent), and conflict-related contributed 8,856 (27.1 percent) (Table 1). Intentional injuries other than those related to conflict were less common. A total of 3,323 fatalities from interpersonal violence were documented in the eight reporting governorates, more than three times as many as from self-harm (958). Two thousand five hundred sixty-six (7.9 percent) of fatalities were of an undetermined intent.

Common mechanisms of injury differed by intent category (Table 1). The most common mechanism of unintentional injury was traffic, followed by burns, electric, and drowning. Gunfire was the most common mechanism of conflict-related fatalities, causing 67.9 percent of deaths, twice as many as explosives. Gunfire was also the most common mechanism (61.1 percent) of interpersonal violence. By contrast, less than a quarter (22.7 percent) of self- 
harm fatalities was caused by gunfire. Burning was the most common mechanism (45.5 percent) of self-harm.

The structure of injury differed by sex and age. Among males, conflict-related fatalities accounted for 33.0 percent of fatalities, more than either unintentional category-road traffic (26.2 percent) or other unintentional injuries (21.3 percent). By contrast, nearly two thirds of fatalities among females were unintentional including 20.0 percent from road traffic and 44.9 percent from other unintentional. The proportion of fatalities attributable to conflict was three times that for males relative to females. The proportion of injuries from interpersonal violence relative to self-harm is also notably different by gender. Among males, the proportion of deaths from interpersonal violence (10.6 percent) was nearly six times that of self-harm (1.8 percent); among females, the proportions were less distinct (9.0 percent and 6.0 percent, respectively). The mechanism of injury within each intention category also showed interesting differences by gender. For example, while burns were the most common mechanism of injury for both other unintentional and self-harm for women, for males, electric and gun fire were more common for these intent categories, respectively.

The structure of injuries among children younger than 15 years more closely resembled that of females than males. Like in women, the unintentional injury categories represented greater proportions of fatalities than intentional injury categories. Among children, unintentional injuries represented nearly 80 percent of all fatalities including both road traffic ( 35.6 percent) and other unintentional injuries ( 43.7 percent). The proportion of fatalities from conflict (7.3 percent), interpersonal violence ( 4.0 percent), and self-harm (1.6 percent) was lower for children than adults (Table 1 and Figure 2). However, among adults aged 55 and older, the majority of injury fatalities were unintentional.

The number of fatal injuries remained stable during the first 3 years under study; coroners documented a total of 7,594, 7,480, and 7,822 injury fatalities in 2010, 2011, and 2012, respectively. However, between 2012 and 2013, the total number of fatalities increased by nearly 25 percent to 9,768. Annual trends in terms of number of fatalities by intention are presented in Figure 3. As shown, the increase in injury fatalities in 2013 was primarily due to a rise in violence. Between 2012 and 2013, the number of fatalities from interpersonal violence increased by 115.8 percent and the number of fatalities from conflict-related injuries increased by 72.3 percent. During the same period, changes in the other injury categories were more gradual-17.1 percent decline in road traffic injuries, 9.4 percent rise in other unintentional injuries, and a 6.3 percent decline in self-harm.

\section{Discussion}

More than a quarter of all injury fatalities reported in eight Iraqi governorates between 2010 and 2013 were attributable to conflict. The number and proportion of fatalities from conflict were approximately equal to that from road traffic and that from other unintentional injuries. Even in 2013, during the resurgence of conflict, unintentional injuries including road traffic resulted in significantly more fatalities than violence. Relative to other conflict-affected countries in the region, however, the proportion of fatalities attributed to violence in Iraq is very high—more than double that from Afghanistan and Libya during the peak of both 
conflicts, and nearly five times that of Yemen. In Afghanistan in 2010, during the height of insurgency activity and surge of US troops, violence-related fatalities were responsible for approximately 11 percent of injury fatalities. ${ }^{15,16}$ In Libya in 2013, amid violence spurred by the Arab Spring protests, an estimated 13 percent of injury fatalities were violence related. ${ }^{15}$ In Yemen, the proportion of fatalities from conflict increased from 5.5 percent in 2010, prior to the 2011 uprisings, to 5.9 percent in 2013. Among countries in the region experiencing conflict, only Syria experienced a higher proportion of conflict-related injuries than Iraq. ${ }^{15}$ While many indicators measure the magnitude of conflict, examining the violence from conflict as a proportion of all injury fatalities provides a different lens which emphasizes the relative strain on the health system.

We also examined nonconflict-related fatalities to explore whether the structure of these injuries showed patterns similar to that of other countries in the region of similar socioeconomic status not affected by conflict. Our analysis suggests that there are several notable differences. First, the proportion of interpersonal violence in Iraq is high compared to other middle income countries in the region. In Iraq, 10.2 percent of all fatal injuries, or 14.0 percent of all non-conflict fatal injuries, were attributed to interpersonal violence. By comparison, in Iran 6.3 percent of fatalities in 2013 were attributed to interpersonal violence. Approximately 7.4 percent of injury fatalities from Syria in 2010, prior to the outbreak of civil war, were attributed to interpersonal violence. The proportion of fatalities from interpersonal violence in Iraq were double regional estimates (5.0 percent of all fatal injuries and 6.4 percent of nonconflict fatal injuries). This finding is consistent with previous research, including an analysis of time series data from over 100 countries, which has documented an increase in interpersonal violence following outbreaks of war and conflict. ${ }^{17}$ Increased nonconflict-related violence may be attributed to increased accessibility of weapons and ammunition, as well as changes in the culture and religious freedoms of a population during conflict. ${ }^{18}$ Damage to health infrastructure and prehospital care may also affect the ability to treat severe injuries and therefore the lethality of violent injuries.

The small number and proportion of self-harm fatalities is another notable anomaly in the Iraq data. During the 4 years, we documented fewer than 1,000 fatal injuries from self-harm in the eight reporting governorates, 3 percent of all injury fatalities. Worldwide self-harm is reported to be one of the leading injury-related causes of death. ${ }^{19}$ While rates of self-harm were reportedly lower in the Eastern Mediterranean Region than other regions, available data suggest that even in the region we should expect at least as many fatalities from self-harm as from interpersonal violence in nonconflict countries. ${ }^{2}$ Global Burden of Disease (GBD) data from Iran, for example, suggest self-harm was responsible for 12.0 percent of fatal injuries in 2013, with 1.9 times more deaths from self-harm than interpersonal violence. Surveillance data from 10 randomly selected provinces in Iran independently documented 1.6 times more deaths from self-harm than interpersonal violence. ${ }^{20}$ Regional estimates suggest that selfharm is responsible for nearly 5 percent of all fatal injuries in low- and middle-income countries in the region, with 1.4 times more deaths attributable to self-harm than interpersonal violence. ${ }^{2}$ In Iraq, by contrast, we documented more than three times more fatalities from interpersonal violence than from self-harm. This may be related to the degree to which cultural beliefs and religious sanctions discourage the practice of self-harm. ${ }^{21,22}$ The same cultural and religious beliefs may also discourage reporting. Previous research 
suggests that underreporting of self-harm may vary considerably by country. ${ }^{23}$ Elevated rates of interpersonal violence may also contribute to the high proportion of interpersonal violence relative to self-harm.

Patterns of unintentional injuries appear to be less affected by conflict than intentional injuries. For example, the proportion of all unintentional injury fatalities that are due to road traffic in our data from Iraq (47.0 percent) is similar to that of both conflict-affected countries such as Yemen (55.5 percent in 2013) and nonconflict-affected countries such as Iran (55.0 percent in 2013). Regionally, 42.2 percent of unintentional fatalities were road traffic related. ${ }^{15}$

Annual trends in unintentional injuries appear to be distinct from trends in violence and insurgency activity. Between 2010 and 2012, a period characterized by consistent, low levels of violence relative to the peak of the Iraq war, the numbers and proportions of injuries for all intent categories remained relatively stable. ${ }^{5,11}$ Consistent with reports of escalating violence, the number of reported fatalities from conflict increased dramatically in $2013 .{ }^{11}$ Our data provide new evidence suggesting that fatalities from interpersonal violence increased concurrently, more than doubling between 2012 and 2013. However, the number and proportion of unintentional injuries did not follow the same trend, but rather experienced only minor changes.

Overall, fatalities in Iraq were predominantly adult males-73.0 percent were male and 76.7 percent were 15 years of age or older. The overall trends therefore mask important differences in the profile of injuries among other demographic groups. A key distinction is the smaller proportion of fatalities from conflict among women and children compared to men and adults, respectively. Among women, there were nearly two fatalities from road traffic and four from other unintentional injury for every conflict-related death. The proportion of fatalities attributed to conflict was 3.2 times higher among men than women. This distinction is unique to Iraq; in other conflict-affected countries, the proportion of fatalities from conflict was greater for women than men. For example, among women in Afghanistan 18.1 percent of injury fatalities were conflict related, twice the proportion among men. ${ }^{15}$ The proportion of fatalities attributed to conflict was also higher among women than men during times of conflict in Yemen, Libya, Pakistan, and Syria. ${ }^{15}$

Injury fatalities were highest for persons in the 5-year age categories from 20 to 34 years. Young adults represent a larger proportion of injury fatalities in Iraq than in the region as a whole, likely due in part to the ongoing conflict. For adults, age 20-34, more than a third of fatalities were conflict related. The proportion of fatalities from conflict among children in Iraq is less than that of adults. The proportion of fatalities from conflict among children ( 7.3 percent) is one fourth that of adults (29.8 percent). The age difference is more pronounced in Iraq compared to other conflict-affected countries. In Yemen, for example, among children, 5.7 percent of fatalities are attributed to conflict, compared to 5.9 percent overall. ${ }^{15}$ Similarly in Libya, among children, 13.0 percent of injuries were conflict-related compared to 13.2 percent overall. 
The findings presented here may be subject to several limitations. First, some fatalities may not be captured by the surveillance system. Registration of all births and deaths is compulsory in Iraq. ${ }^{24-26}$ However, despite these legal provisions, there remains the possibility of unreported deaths. Second, to evaluate the relative burden of injury mechanisms for each demographic group, we present proportionate mortality. Updated population estimates by governorate by sex or age are unavailable, precluding us from calculating sex- or age-specific fatality rates or age-adjusted estimates. Third, sensitivity of the surveillance system may vary by intent or mechanism categories. ${ }^{27}$ Such differences would influence the interpretability of proportions presented in our analysis. Fourth, coroners only report the primary cause of death; underlying causes that may have initiated the events resulting in death (eg, rape or attempted rape) are not reported. This may mask the impact of injuries such as sexual assault. Fifth, legal intervention was not collected; the demographic profile of these fatalities may be distinct from other injuries. Finally, few countries in the region have fatal injury surveillance data. Where data are reported, they are often of low quality with a high proportion coded as unknown intent or mechanism; these data had only 8 percent undetermined intent. Interpretation of our data, therefore, relies heavily on comparisons to GBD project data, estimates based on multiple data sources. We suggest that the relative proportions provide valid comparisons, however, that may not be a valid assumption particularly in the case of countries with poor primary data sources.

Descriptive analysis of injury surveillance data can help answer important questions regarding the magnitude of mortality, relative mortality by cause, differences in mortality by age and sex, as well as trends. Reports describing the patterns of injuries in high-income countries highlight the importance of this information for prevention program planning; similar efforts in low- and middle-income countries remain limited. ${ }^{28,29}$ Data presented here represent an effort to better understand the effect of conflict on injury fatalities. Nearly a quarter of injury fatalities in Iraq were attributable to conflict, a higher proportion than reported in most conflict-affected countries. Potentially as a consequence of the high burden of conflict sustained over more than a decade, the overall profile of nonconflict injuries in Iraq has important distinctions when compared to other countries in the region that are not affected by conflict. Given these differences, regional data cannot be readily extrapolated and used in Iraq; collection of high-quality routine national injury data is therefore essential for public health programming in injury prevention.

\section{Acknowledgments}

We thank all focal points at all coroner offices and emergency departments for their long standing commitments in collecting data from victims of injury in Iraq, as well as the Director of the Operational Center and the Director General of Medical Operation and Specialized Services, Iraqi Ministry of Health, for their logistics support of the Iraqi Injury Surveillance System. The views expressed are those of the authors and do not necessarily represent the policy of the US Centers for Disease Control and Prevention, the World Health Organization, and Ministry of Health, Iraq. All authors declare that they have no competing interests; no support from any organisation for the submitted work; no financial relationships with any organizations that might have an interest in the submitted work in the previous 3 years; no other relationships or activities that could appear to have influenced the submitted work. OOB, ASSS, AH, SJH, and EL designed the study, ASSS and AH collected the data, OOB, ASSS, AH, and EL analyzed the data, OOB and EL interpreted the data, OOB and EL drafted the manuscript, and ASSS, AH, and SJH critically revised the manuscript for important intellectual content. OOB, ASSS, AH, SJH, and EL read and approved the final manuscript. OOB is a guarantor. All authors had full access to all of the data and take responsibility for the integrity of the data and the accuracy of the data analysis. This study was exempted from review by the Institutional Review Board of the Centers for Disease Control and Prevention as the primary intent 
was surveillance and was determined to not involve human subject research. The study constitutes a secondary analysis of surveillance data routinely collected for programmatic purposes.

\section{References}

1. The Work Bank: Work Bank Country and lending groups. Secondary country and lending groups 2015. Available at https://datahelpdesk.worldbank.org/knowledgebase/articles/906519-world-bankcountry-and-lending-groups. Accessed July 7, 2016

2. Norton R, Kobusingye O. Injuries. N Engl J Med. 2013; 368(18):1723-1730. [PubMed: 23635052]

3. World Health Organization (WHO). Cause-specific mortality: Regional estimates for 2008. Geneva: World Health Organization; Available at http://www.who.int/healthinfo/global_burden_disease/ estimates_regional_2004_2008/en/. Accessed July 7, 2016

4. Bhalla K, Harrison JE, Shahraz S, et al. Availability and quality of cause-of-death data for estimating the global burden of injuries. Bull World Health Organ. 2010; 88(11):831-838C. [PubMed: 21076564]

5. Hagopian A, Flaxman AD, Takaro TK, et al. Mortality in Iraq associated with the 2003-2011 war and occupation: Findings from a national cluster sample survey by the university collaborative Iraq Mortality Study. PLoS Med. 2013; 10(10):e1001533. [PubMed: 24143140]

6. Burnham G, Lafta R, Doocy S, et al. Mortality after the 2003 invasion of Iraq: A cross-sectional cluster sample survey. Lancet. 2006; 368(9545):1421-1428. [PubMed: 17055943]

7. Roberts L, Lafta R, Garfield R, et al. Mortality before and after the 2003 invasion of Iraq: Cluster sample survey. Lancet. 2004; 364(9448):1857-1864. [PubMed: 15555665]

8. Iraq Body Count (IBC). Iraqi deaths from violence 2003-2011: Analysis and overview from Iraq Body Count. 2012. Available at http://www.iraqbodycount.org/analysis/numbers/2011. Accessed November 1, 2015

9. Hicks MH. Mortality in Iraq. Lancet. 2007; 369(9556):101-102.

10. Iraq Body Count (IBC). Iraq 2014: Civilian deaths almost doubling year on year. 2015. Available at https://www.iraqbodycount.org/analysis/numbers/2014. Accessed November 1, 2015

11. Bilukha O, Leidman E, Sultan AS, et al. Deaths due to intentional explosions in selected governorates of Iraq from 2010 to 2013: Prospective surveillance. Prehosp Disaster Med. 2015; 30(6):586-592. [PubMed: 26517290]

12. Central Organization for Statistics and Information Technology (COSIT). Section 2: Population census. Annual abstract of statistics 2010-2011. 2012. Available at http://cosit.gov.iq/AAS/ section_2.php. Accessed November 1, 2015

13. United Nations Joint Analysis Unit. Iraq Information Portal. Governorate Profile; 2012. Available at: http://www.iau-iraq.org/gp/. Accessed July 7, 2016

14. Global Burden of Disease Study 2013. Global Burden of Disease Study 2013 (GBD 2013) AgeSex Specific All-Cause and Cause-Specific Mortality 1990-2013. Seattle, WA: Institute for Health Metrics and Evaluation; 2014.

15. Institute for Health Metrics Evaluation (IHME). GBD Compare. Seattle, WA: IHME, University of Washington; 2015. Available at http://vizhub.healthdata.org/gbd-compare. Accessed November 1, 2015

16. Nordland R. An uncharacteristically upbeat general in Afghanistan. New York Times. Jan 24.2001 Sect At War.

17. Archer D, Gartner R. Violent acts and violent times: A comparative approach to postwar homicide rates. Am Soc Rev. 1976; 41(6):937-963.

18. Krug, EG., Dahlberg, LL., Mercy, JA., et al. World report on violence and health. Geneva: World Health Organization; 2002. Available at http://www.who.int/violence_injury_prevention/violence/ world_report/. Accessed November 17, 2015

19. Krug, EG., editor. Injury: A leading cause of the global burden of disease. Geneva: World Health Organization; 1999. Available at http://apps.who.int/iris/handle/10665/66160. Accessed November 17,2015

20. Akbari ME, Naghavi M, Soori H. Epidemiology of deaths from injuries in the Islamic Republic of Iran. East Mediterr Health J. 2006; 12(3-4):382-390. [PubMed: 17037707] 
21. Kipsaina C, Eze UO, Ozanne-Smith J. A standardised mortuary-based injury surveillance system: Lessons learned from the Ibadan Nigerian trial. Int J Inj Contr Saf Promot. 2015; 22(3):193-202. [PubMed: 24533636]

22. Bell, J., Lugo, L., Cooperman, A., et al. The World's Muslims: Religion, politics and society. Pew Research Center; 2013. Available at http://www.pewforum.org/2013/04/30/the-worlds-muslimsreligion-politics-society-morality/. Accessed March 17, 2016

23. De Leo D. Can we rely on suicide mortality data? Crisis. 2015; 36(1):1-3. [PubMed: 25653086]

24. Medico-Legal Law No. (37). Secondary Medico-Legal Law No. (37) for the year. 2013. Available at http://www.iraq-lg-law.org/ar/taxonomy/term/108. Accessed November 1, 2015

25. Ministry of Health Civil Status Directorate. Death Certificates: Reporting and registration of births and applying for copies of birth certificate: Iraq E-Government Portal. 2013. Available at http:// www.egov.gov.iq/egov-iraq. Accessed November 1, 2015

26. Al-Rabie, AS. Registration of vital events in Iraq Secondary registration of vital events in Iraq. 1980. Available at http://www.cdc.gov/nchs/data/isp/010_Registration_of_ \%20Vital_Events_in_Iraq.pdf. Accessed November 1, 2015

27. Farooq U, Majeed M, Bhatti JA, et al. Differences in reporting of violence and deliberate self harm related injuries to health and police authorities, Rawalpindi, Pakistan. PloS One. 2010; 5(2):e9373. [PubMed: 20186326]

28. Vyrostek SB, Annest JL, Ryan GW. Surveillance for fatal and nonfatal injuries-United States, 2001. MMWR Surveill Summ. 2004; 53:1-57.

29. Krug EG. Injury surveillance is key to preventing injuries. Lancet. 2004; 364(9445):1563-1566. [PubMed: 15519616] 


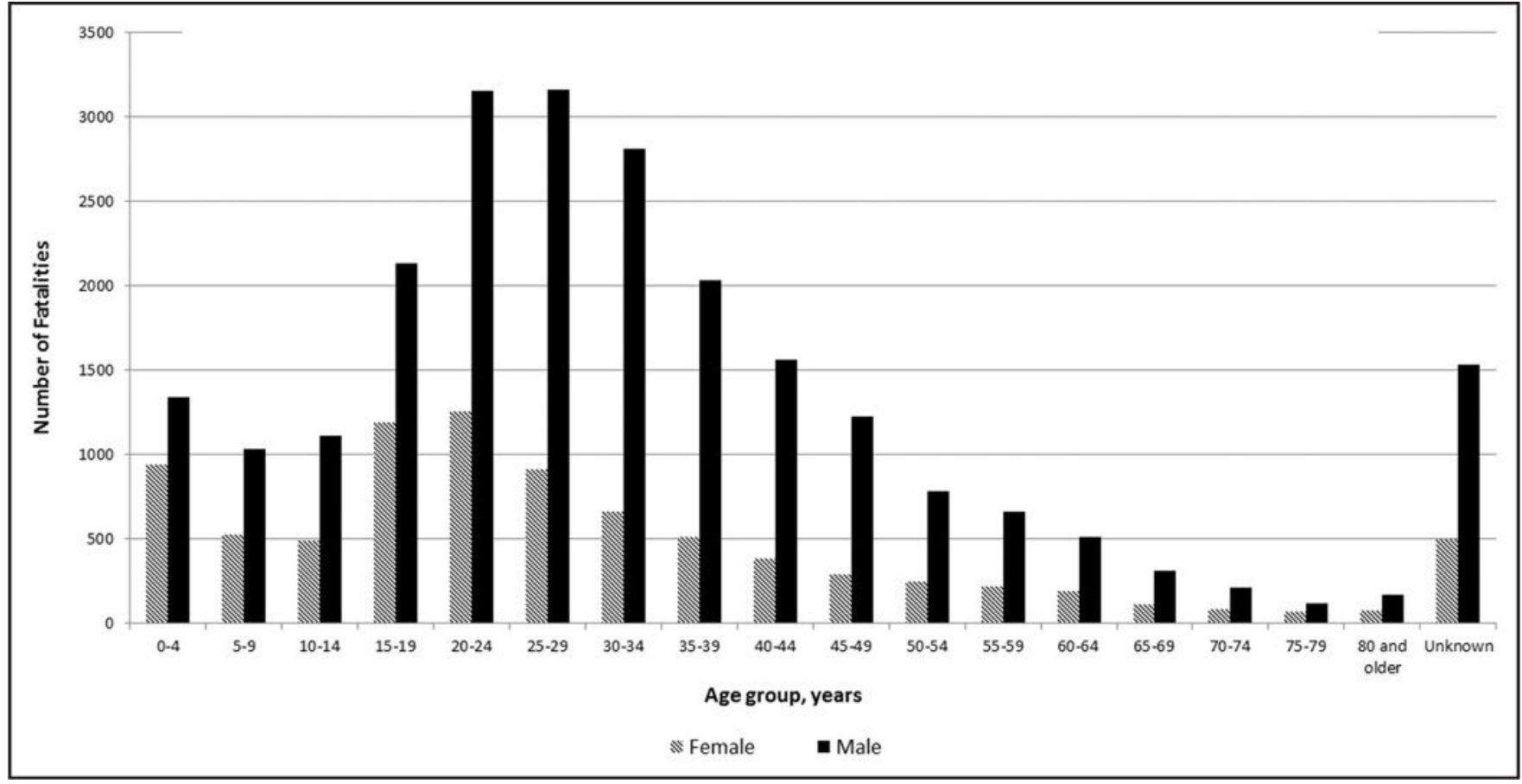

Figure 1.

Age and sex distribution of injury deaths in Iraq, 2010-2013. One hundred forty-two (0.43 percent) fatalities with unknown gender are not shown. 


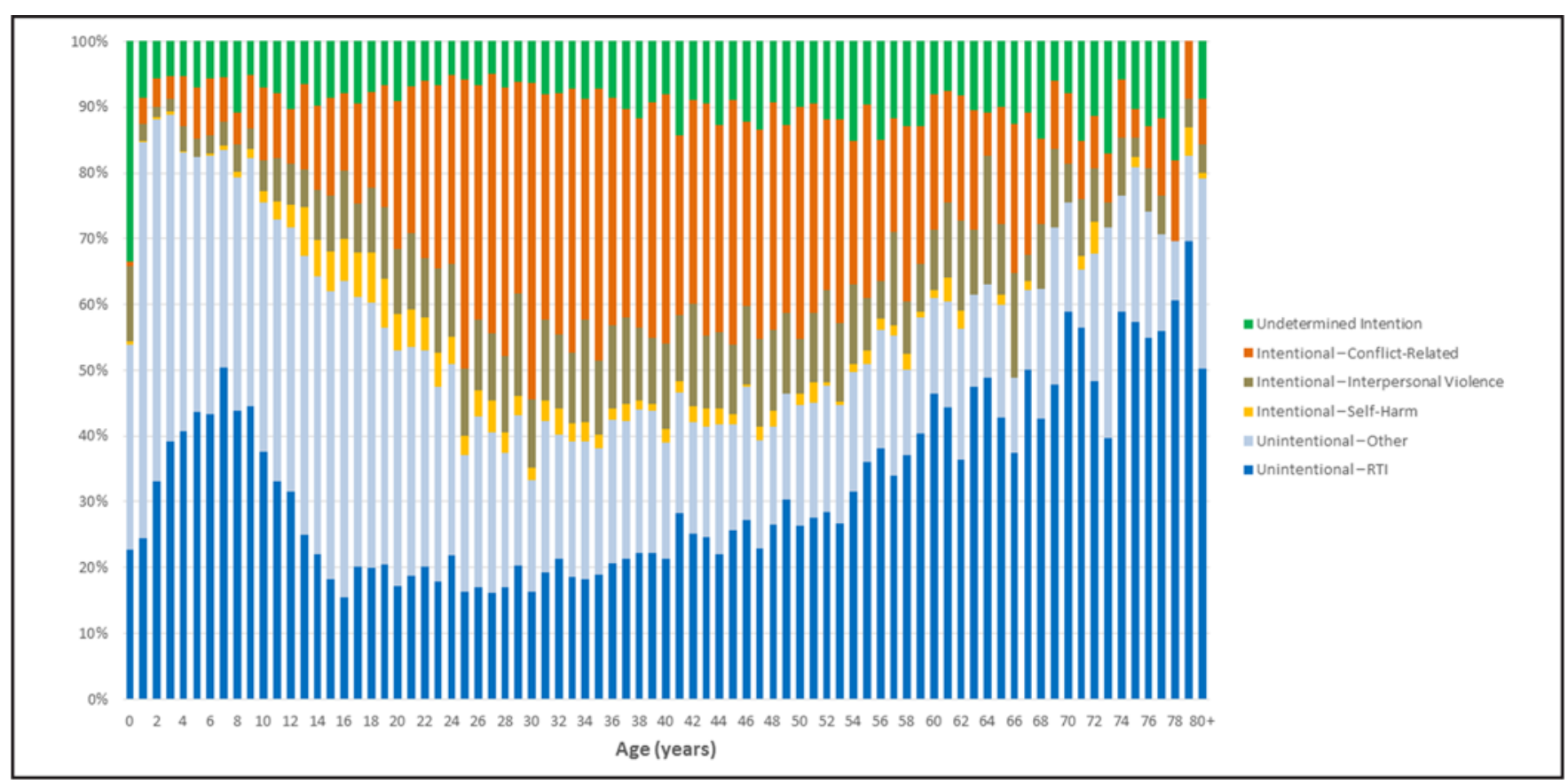

Figure 2.

Proportion of fatalities, by intention and age, Iraq, 2010-2013. The relative proportion of injury fatalities attributed to each intention category by age of the fatality. Two thousand one hundred sixty-two (6.6 percent) fatalities with undetermined age are not shown. 


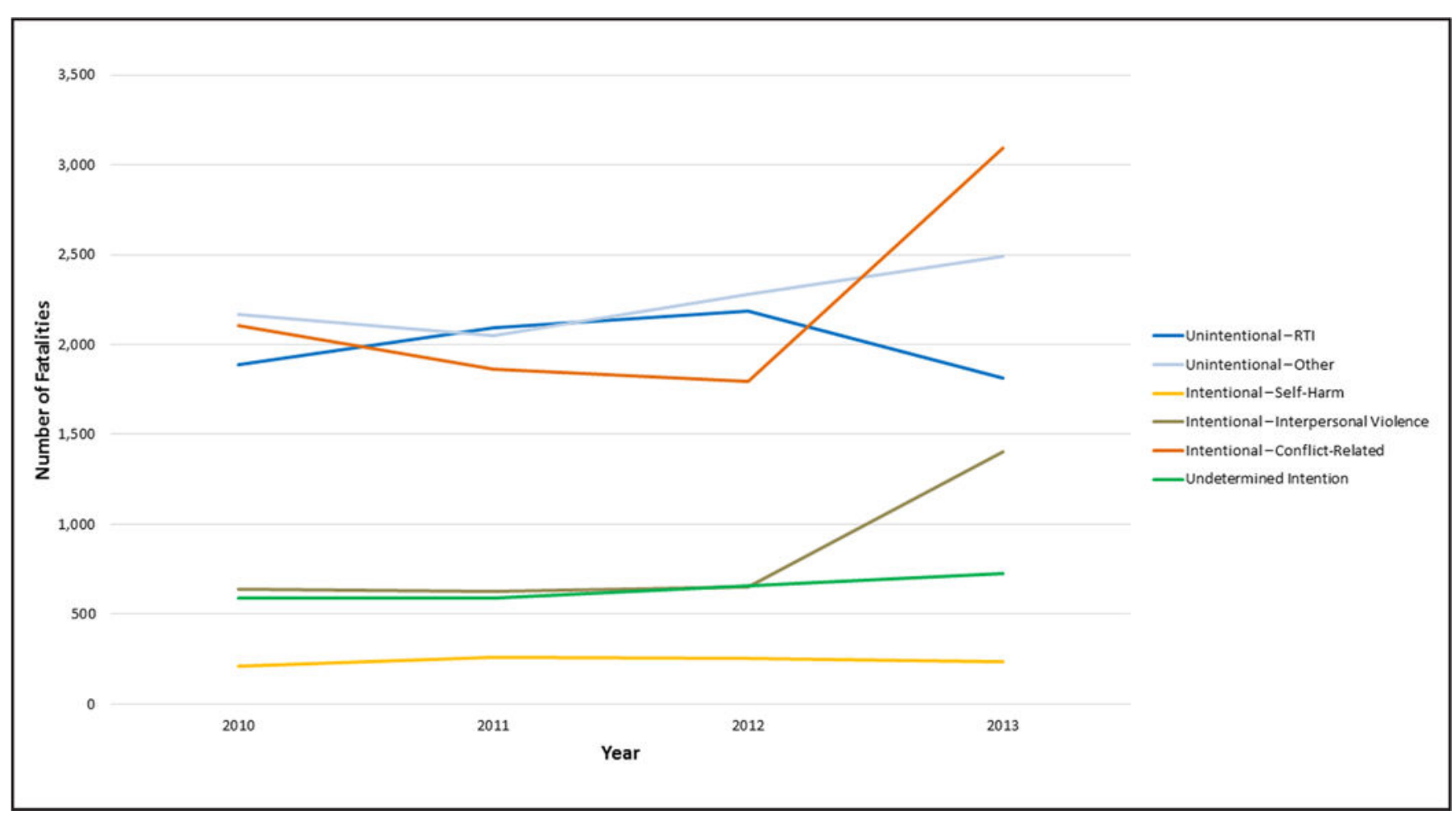

Figure 3.

Number of fatalities, by year and intention, Iraq, 2010-2013. 


\begin{tabular}{|c|c|c|c|c|c|c|c|c|c|c|c|c|c|c|c|c|c|c|c|c|c|c|c|c|c|}
\hline$\frac{\vec{E}}{4}$ & $\stackrel{x}{\circ}$ & $\begin{array}{l}\infty \\
\text { î. } \\
\text { in }\end{array}$ & $\begin{array}{l}\infty \\
\stackrel{+}{d}\end{array}$ & 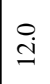 & $\dot{0}$ & $\stackrel{+}{\mathrm{i}}$ & $\stackrel{+}{-}$ & $\hat{i}$ & $\overrightarrow{0}$ & $\hat{\varrho}$ & $\vec{r}$ & $\stackrel{9}{-}$ & $\stackrel{\infty}{-}$ & $\stackrel{\circ}{\circ}$ & $\stackrel{\rightleftarrows}{m}$ & $\stackrel{\circ}{-}$ & $\stackrel{\infty}{\circ}$ & $\stackrel{\circ}{-}$ & $\stackrel{0}{0}$ & $\begin{array}{l}\infty \\
\stackrel{i}{0}\end{array}$ & $\begin{array}{l}0 \\
\stackrel{\sim}{0}\end{array}$ & $\stackrel{\infty}{+}$ & + & $\stackrel{\circ}{\circ}$ & $\infty$ \\
\hline 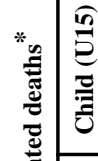 & $\frac{1}{\hat{\sigma}}$ & $\begin{array}{l}0 \\
\dot{m} \\
\dot{m}\end{array}$ & $\stackrel{\grave{f}}{\dot{y}}$ & $\stackrel{i}{i}$ & $\dot{\alpha}$ & $\stackrel{\circ}{i}$ & $\vec{m}$ & $\stackrel{?}{?}$ & $\overrightarrow{0}$ & $\stackrel{\circ}{+}$ & $\stackrel{\nexists}{-}$ & $\stackrel{0}{0}$ & 9 & $\overline{0}$ & . & 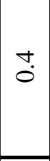 & กั & o & $\because$ & $\stackrel{?}{?}$ & $\dot{m}$ & $\vec{i}$ & $\stackrel{\infty}{\rightarrow}$ & $\stackrel{\circ}{\circ}$ & $\stackrel{2}{\pi}$ \\
\hline 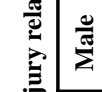 & 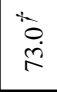 & ב̃ & $\frac{m}{\sim}$ & $\vec{n}$ & $\stackrel{i}{\therefore}$ & $\mid \stackrel{\infty}{\sim}$ & $\stackrel{\infty}{\stackrel{\infty}{.}}$ & 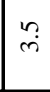 & $\overrightarrow{0}$ & $\stackrel{\bullet}{\stackrel{0}{0}}$ & 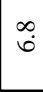 & $\stackrel{\infty}{-}$ & $\stackrel{\leftrightarrow}{i}$ & $\overline{0}$ & $\stackrel{\infty}{\sim}$ & $\stackrel{m}{0}$ & $\hat{o}$ & $\stackrel{\infty}{0}$ & $\because$ & 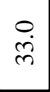 & $\begin{array}{l}\text { ते } \\
\text { an }\end{array}$ & $\stackrel{t}{\varrho}$ & ? & $\stackrel{0}{\circ}$ & $\bar{r}$ \\
\hline 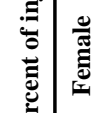 & $\mid \begin{array}{l}1 \\
10 \\
0 \\
0\end{array}$ & $\stackrel{\circ}{\dot{\sim}}$ & $\underset{\dot{f}}{\dot{f}}$ & $\underset{\text { in }}{\text { in }}$ & $n$ & 9 & . & $\dot{m}$ & $\overrightarrow{0}$ & $\stackrel{\circ}{\circ}$ & $\stackrel{F}{f}$ & $\stackrel{0}{-1}$ & $\begin{array}{l}0 \\
i\end{array}$ & $\overline{0}$ & : & $\stackrel{m}{+}$ & $\stackrel{\circ}{\circ}$ & $\stackrel{\sim}{工}$ & $\because$ & $\stackrel{m}{\varrho}$ & $\begin{array}{l}0 \\
\infty\end{array}$ & $\vec{i}$ & $\overrightarrow{0}$ & $\stackrel{0}{\circ}$ & $\begin{array}{l}\infty \\
0 \\
0\end{array}$ \\
\hline 吾 & 客 & $\mid \begin{array}{l}+ \\
\dot{d}\end{array}$ & $\begin{array}{l}n \\
\stackrel{n}{\sim}\end{array}$ & 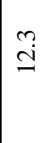 & $\begin{array}{l}0 \\
0 \\
0\end{array}$ & $\stackrel{m}{m}$ & $\stackrel{\infty}{\rightarrow}$ & ర్లా & $\overrightarrow{0}$ & 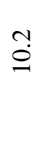 & గु & 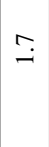 & $\tilde{\mathrm{i}}$ & $\overline{0}$ & $\vec{i}$ & $\stackrel{m}{-}$ & $\tilde{0}$ & o & $\because$ & $\overrightarrow{\vec{\lambda}}$ & $\mid \begin{array}{l}+ \\
\infty \\
\sim\end{array}$ & $\stackrel{+}{\infty}$ & ֻु. & $\stackrel{0}{\circ}$ & $\stackrel{2}{r}$ \\
\hline 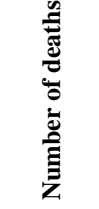 & $\begin{array}{l}\text { Jे } \\
\text { c. } \\
\text { i }\end{array}$ & $\begin{array}{l}0 \\
2 \\
2 \\
\end{array}$ & $\begin{array}{l}\infty \\
\infty \\
\infty \\
\infty\end{array}$ & \begin{tabular}{|l}
$\tilde{\delta}$ \\
$\dot{\sigma}$ \\
+
\end{tabular} & $\frac{\infty}{i}$ & : & 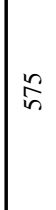 & $\stackrel{n}{=}$ & $\cong$ & $\stackrel{\overbrace{}}{\approx}$ & $\begin{array}{l}\stackrel{\rho}{0} \\
i\end{array}$ & in & 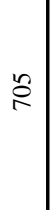 & $\stackrel{\infty}{=}$ & 祭 & \begin{tabular}{|l}
0 \\
$⿱ 亠 乂$ \\
\end{tabular} & $\bar{\sim}$ & $\bar{\sigma}$ & o & $\begin{array}{l}\infty \\
\infty \\
\infty \\
\infty\end{array}$ & $\begin{array}{l}n \\
0 \\
0 \\
0\end{array}$ & $\begin{array}{l}\stackrel{n}{\hat{i}} \\
\hat{i}\end{array}$ & $\vec{\infty}$ & $r$ & \\
\hline 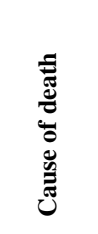 & 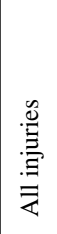 & 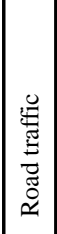 & 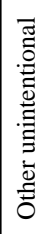 & 兰 & $\begin{array}{l}\frac{0}{0} \\
\frac{0}{\Psi} \\
\underline{y}\end{array}$ & : & 言 & 离 & 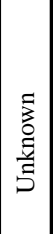 & 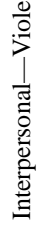 & 怤 & $\begin{array}{l}\frac{n}{0} \\
\frac{0}{0} \\
0 \\
0 \\
\text { : } \\
\frac{\tilde{z}}{n}\end{array}$ & $\begin{array}{l}\bar{\Xi} \\
\bar{t}\end{array}$ & $\begin{array}{l}\text { है } \\
\text { है } \\
\text { है }\end{array}$ & 㽦 & 号 & 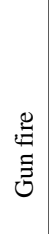 & \begin{tabular}{|l|l}
$\overline{0}$ \\
$\bar{z}$
\end{tabular} & $\begin{array}{l}\text { है } \\
0 \\
\text { ह } \\
\text { है }\end{array}$ & 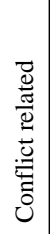 & 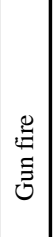 & 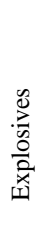 & 离 & $\begin{array}{l}\frac{5}{5} \\
\text { है } \\
\text { है }\end{array}$ & \\
\hline
\end{tabular}



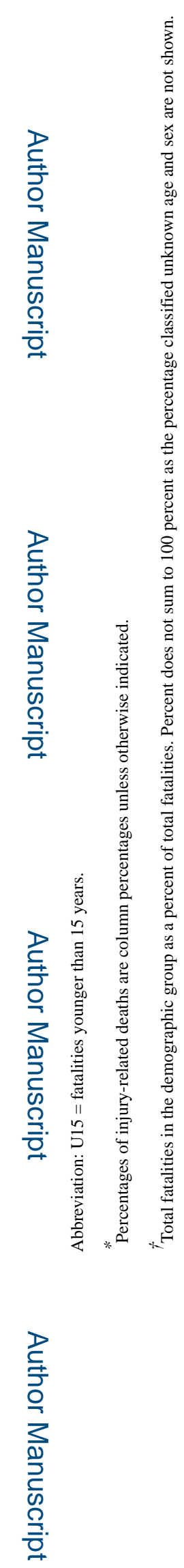

Am J Disaster Med. Author manuscript; available in PMC 2017 May 18. 